\title{
NOVOS PRODUTOS E CORTES DIFERENCIADOS: O POTENCIAL DOS PEIXES NATIVOS NOS MERCADOS DA GASTRONOMIA
}

\author{
Diego Neves de Sousa ${ }^{1}$ \\ Hellen Cristina de Almeida Kato ${ }^{2}$
}

\section{RESUMO}

Este artigo tem como objetivo analisar quais são as estratégias de inserção de peixes nativos nos mercados diferenciados da gastronomia, sob a perspectiva das pesquisas realizadas pela EMBRAPA (Empresa Brasileira de Pesquisa Agropecuária). Na metodologia foram selecionadas três estratégias que foram descritas utilizando-se de dados secundários. Entre os resultados, postula-se que as estratégias de substituição de produtos globais por locais, como ocorre com os peixes nativos, novas hibridizações na gastronomia vêm sendo criadas, a partir de novos produtos e novos cortes, acarretando em novas identidades culturais e formas de consumo.

Palavras-chave: alimentação saudável, cadeia produtiva do peixe, gastronomia, produtos locais, sistema agroalimentar.

\section{NEW PRODUCTS AND DIFFERENTIATED CUTS: THE POTENTIAL OF NATIVE FISH IN THE GASTRONOMY MARKETS}

\begin{abstract}
This article aims to analyze the strategies of insertion of native fish in the differentiated markets of gastronomy, from the perspective of the research carried out by EMBRAPA (Brazilian Agricultural Research Corporation). In the methodology, three strategies were selected which were described using secondary data. Among the results, it is postulated that the strategies of replacing global products with local ones, as with native fish, new hybridizations in gastronomy are being created, starting from new products and new cuts, resulting in new cultural identities and forms of consumption.
\end{abstract}

Keywords: agro-alimentary system, gastronomy, healthy food, local products, productive chain of fish.

\footnotetext{
1 Graduado em Gestão de Cooperativas (UFV). Mestre em Extensão Rural (UFV). Doutorando em Desenvolvimento Rural (UFRGS). Analista da Embrapa Pesca e Aquicultura. E-mail: diego.sousa@embrapa.br.

${ }_{2}^{2}$ Graduada em Medicina Veterinária (UFRA). Mestre em Ciência e Tecnologia de Alimentos (UFPA). Pesquisadora da Embrapa Pesca e Aquicultura. E-mail: hellen.almeida@embrapa.br.
} 


\section{INTRODUÇÃO}

No Brasil, o consumo de pescados, grupo que inclui peixes, crustáceos (camarão, caranguejos e siris) e moluscos (polvos, lulas, ostras, mariscos) provenientes de água doce e marinha, ainda tem o consumo muito restrito a seu principal representante, os peixes devido à maior facilidade com que estes chegam ao mercado, tornando-se mais populares (BRASIL, 2014).

O pescado, desde as últimas décadas, se destaca mundialmente no comércio de alimentos de produtos preparados, processados e semi-processados. Com essa tendência no sistema agroalimentar, o pescado se tornou uma importante opção no portfólio de "pratos de refeição", fomentado diretamente por empresas multinacionais e popularizando o seu consumo por meio da comercialização nos supermercados. Por isso, verifica-se que na coordenação da cadeia produtiva do pescado existe uma hegemonia das grandes redes de supermercados impondo caminhos aos sistemas agroalimentares, principalmente em países subdesenvolvidos (WILKINSON, 2006).

Segundo dados da Organização das Nações Unidas para a Alimentação e a Agricultura (FAO), em nível global, o pescado corresponde a mais de $9 \%$ do total de exportações agrícolas e $1 \%$ do comércio mundial de mercadorias em termos de valor. Há décadas este é um dos produtos alimentares mais comercializados no mundo, com $54 \%$ do valor das exportações originária de países em desenvolvimento, nos quais tem importante papel na geração de renda, emprego, segurança alimentar e nutricional. Em 2014, as exportações de pesca dos países em desenvolvimento foram avaliadas em US $\$ 80$ bilhões de dólares, e suas receitas de exportação de pescado somaram US\$ 42 bilhões de dólares, superiores a importantes commodities agrícolas (carne, tabaco, arroz e açúcar) combinadas (SOFIA, 2016).

Esses dados demonstram que o pescado é uma das principais proteínas na dieta alimentar dos países desenvolvidos, no qual o consumo em 2013, foi de 26,8 $\mathrm{kg}$ per capita, enquanto nos países em desenvolvimento, teve-se consumo médio de 18,8 kg per capita. No Brasil, verificou-se uma evolução no consumo per capita no período de 1993 a 2013, no qual o aumento do consumo nacional de pescado mais que dobrou, alcançando o crescimento de 103,9\% (FAOSTAT, 2016).

A cadeia alimentar do pescado cresceu graças as técnicas da aquicultura, estimulada como alternativa à produção da pesca, que entrou em declínio nos anos 90, devido à pressão de pesca e redução dos estoques, tornando-se cada vez mais necessárias estratégias de manejo e acordos de pesca sustentáveis. Além disso, enquanto na pesca extrativa não se sabe a quantidade de peixe a ser capturada, na aquicultura há maior controle no planejamento da despesca, volume e uniformidade do produto a ser obtido (SOUSA, 2014). Essas vantagens conduziram a uma migração do extrativismo para a produção intensiva, que Wilkinson (2006) denominou de Revolução Azul em analogia à Revolução Verde que tinha como horizonte modernizar a produção agropecuária com o propósito de especializar e aumentar a escala de produção.

Diante desse cenário, o pescado tornou-se matéria-prima em potencial nos nichos de mercados gastronômicos, dado que este produto se integra cada vez mais as cadeias globais devido à melhoria da qualidade, disponibilidade, uniformidade e aos novos produtos e cortes diferenciados desenvolvidos, de acordo com características inerentes às inúmeras espécies, se colocando como alternativa de ingrediente em um número cada vez maior de cozinhas.

No cenário gastronômico atual, em contrapartida ao processo de unificar os sabores e padronizar a produção de alimentos, conforme explica Zuin e Zuin (2008), 
há uma grande demanda por valorização dos produtos locais, também conhecidos como tradicionais ou típicos de uma determina região, que crescem em consonância a construção de mercados alternativos, com o intuito de mobilizar significados e demarcar identidades a partir dos alimentos de uma determinada localidade.

Assim, esse aumento na demanda por produtos de origem local é de fundamental importância para continuar a (re)produção de espécies nativas (animais ou vegetais), bem como o saber e o modo de fazer transmitido por gerações que envolvem a produção dessa importante matéria-prima cada vez mais valorizada por sua qualidade nutricional, considerada rica em proteínas de alto valor biológico e minerais (KATO; FREITAS, 2015).

As espécies nativas têm um grande potencial produtivo, pois são espécies oriundas da biodiversidade local e, por isso, bem adaptadas às condições climáticas de produção, mas que ainda não possuem o pacote tecnológico adequado para sua produção em larga escala ou não são adequadamente valoradas ao competir com pescados importados ou com espécies exóticas produzidas no país.

No Brasil, a tilápia (Oreochromis niloticus), espécie exótica originária do norte da África, é a mais cultivada e juntamente com o grande volume de pescado importado todos os anos como salmão (Salmo salar), bacalhau (Gadus morhua), merluza (Merluccius sp) e polaca (Theragra chalcogramma) reduzem o espaço no mercado para as espécies nativas, devido aos seus baixos custos de produção e importação. Os peixes nativos, muitas vezes produzidos em menor escala e em sistemas menos eficientes, tornam-se mais caros e, por isso, perdem a preferência dos consumidores, já que, o consumo de pescados entre a população brasileira apresenta comportamento elástico. Ou seja, o preço do produto possui influência direta na sua curva de oferta e demanda. Assim, este estudo objetiva analisar quais são as estratégias de inserção de peixes nativos nos mercados diferenciados da gastronomia, sob a perspectiva das pesquisas realizadas pela Embrapa, especificamente na Unidade Pesca e Aquicultura, localizada em Palmas/TO. Para isso, metodologicamente, foram selecionadas três estratégias que foram descritas utilizando de dados secundários.

Neste artigo, a primeira seção tem a finalidade de demonstrar a importância e o crescimento que o pescado tem tido no sistema agroalimentar, tanto na produção como no consumo mundial, além de desenhar esse retrato no Brasil. A segunda seção apresenta as características que referenciam o pescado como alimento saudável. Na terceira seção se discute as perspectivas de inserção de produtos locais e tradicionais na gastronomia internacional e em mercados de nichos. Na quarta seção o objetivo é trazer as experiências de pesquisas que a Embrapa está realizando com peixes nativos para serem introduzidos nos mercados: da alimentação escolar, da indústria conserveira e da culinária japonesa. E, por último, as considerações finais sobre a potencialidade dos peixes nativos para a gastronomia.

\section{O PESCADO COMO REFERÊNCIA DE ALIMENTAÇÃO SAUDÁVEL}

Nas últimas décadas, as questões relativas à alimentação e nutrição no Brasil vêm se constituindo num cenário complexo, no qual se observa o fenômeno da transição nutricional. Esse fenômeno é marcado pelo aumento dos índices de obesidade, sobrepeso e Doenças Crônicas Não Transmissíveis (DCNT) (SÁ; MOURA, 2010). Além disso, no âmbito da produção agrícola, encontra-se comprovadamente demonstrado os danos causados pelo modelo agrícola concentrador de terra, caracterizado pela monocultura intensiva, aumento do uso de agrotóxicos e os riscos da utilização de transgênicos. Esse modelo tem forte 
presença no país, o que gera graves consequências socioeconômicas e ambientais para a população (ABRANDH, 2012).

A necessidade energética e de nutrientes são fatores preponderantes a serem considerados na alimentação, especialmente de crianças e adolescentes, uma vez que a energia consumida deve ser equivalente àquela dispendida. Conforme explanado pelo Instituto de Medicina (IOM, 2002), a estimativa de gasto energético requer o conhecimento de distintos critérios, tais como: peso, altura, faixa etária, sexo e nível de atividade física, acrescida da energia necessária para a reposição de tecidos.

Os dados do IBGE (2009) revelam que, nos últimos vinte anos, houve melhoras nos índices de baixo peso e baixa estatura em referência as crianças menores de cinco anos. O padrão considerado aceitável pela Organização Mundial da Saúde (OMS) é que tanto para baixo peso quanto para baixa estatura as proporções devem ser menor que 2,3\%. Algumas regiões do país já se encontram nos padrões adequados, entretanto, estes ainda não foram atingidos nas regiões Norte e Nordeste.

Como um dos motivadores da melhora desses índices encontra-se o Programa Nacional da Alimentação Escolar (PNAE), a partir da Resolução do Conselho Deliberativo do Fundo Nacional de Desenvolvimento da Educação (FNDE), no 32/2006, contribuiu para que houvesse a transferência de recursos financeiros em caráter complementar, de forma a garantir uma refeição diária com aproximadamente 350 quilocalorias e 9 gramas de proteínas aos alunos beneficiários da rede pública de ensino, o que possibilita a cobertura de no mínimo $15 \%$ das necessidades energéticas e nutricionais diárias. Já para os alunos indígenas e quilombolas a meta é alcançar no mínimo $30 \%$. O objetivo desta política pública é atender as necessidades nutricionais dos alunos durante sua permanência em sala de aula, contribuindo para o seu crescimento e desenvolvimento cognitivo; a aprendizagem e o rendimento escolar; a formação de hábitos alimentares saudáveis e adequados, compreendendo o uso de alimentos variados e sua sazonalidade que respeitem a cultura, tradições e hábitos alimentares seguros; dinamização da economia local; respeito aos hábitos regionais e a vocação agrícola da região (BRASIL, 2006).

O estímulo à adoção de modos de vida e hábitos alimentares seguros e saudáveis encontra respaldo na Política Nacional de Alimentação e Nutrição (PNAM) instituída em 1999, vinculada ao Ministério da Saúde, que tem no Guia Alimentar para a População Brasileira, obra elaborada por tal Ministério no ano de 2006, um dos instrumentos de reforço à melhoria dos padrões nutricionais da população (BRASIL, 2009). Uma nova versão deste guia foi lançada em 2014. A atualização está ligada aos cuidados e caminhos recomendados para se alcançar uma alimentação saudável, saborosa e balanceada. Assim, a proposta da publicação é ao invés de trabalhar com grupos alimentares e porções recomendadas, há a indicação de que a alimentação tenha como base alimentos frescos e minimamente processados, além de evitar os ultraprocessados (BRASIL, 2014).

Percebe-se que o consumo do pescado está aquém do adequado, de acordo com os dados supracitados comparando-os aos índices indicados pela Organização das Nações Unidas para Agricultura e Alimentação (FAO). O recomendado é estabelecer a quantia mínima de $12 \mathrm{~kg} / \mathrm{hab} / \mathrm{ano}$ para o indivíduo obter uma vida mais saudável, contudo os dados de 2013 revelam que o consumo nacional de pescado obteve a marca de $10,87 \mathrm{~kg} / \mathrm{hab} / \mathrm{ano}$ (FAOSTAT, 2016).

Por outro lado, verifica-se uma evolução no consumo per capta, conforme é ilustrado na Figura 1, no período de 1993 a 2013, o aumento do consumo nacional 
de pescado mais que dobrou, alcançando o crescimento de 103,9\% (FAOSTAT, 2016).

Figura 1 - Evolução do consumo de pescado per capita no Brasil (1993-2013)

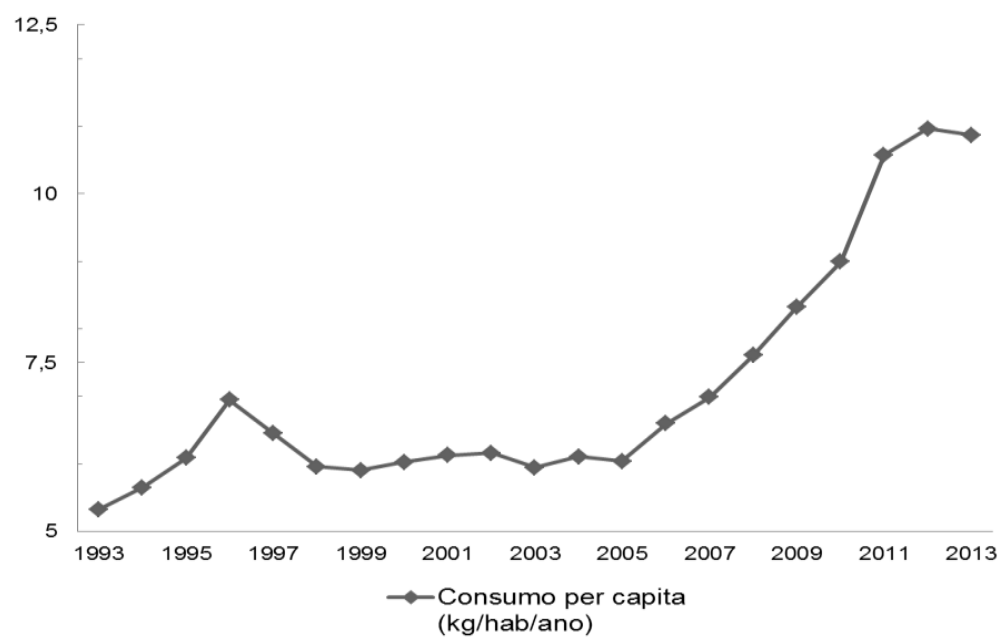

Fonte: FAOSTAT, 2016.

No entanto, apesar do Brasil possuir enorme costa marítima e inúmeros rios de grande porte, em diferentes regiões, a oferta de peixes também é pequena e os preços são relativamente altos em relação às carnes vermelhas e aves. Isto pode explicar a baixa frequência de consumo no país (BRASIL, 2014).

Motivos para esse déficit podem ser a dificuldade e o maior tempo exigido para manipulação e preparo de pratos quando preparados com peixe in natura, dificuldades na armazenagem, por se tratar de um produto altamente perecível e, no caso da alimentação escolar, o receio das escolas em fornecer peixes às crianças, decisão motivada pelo temor de acidentes com a ingestão de espinhas. Por esse motivo, a inserção do pescado neste mercado, passa pelo desenvolvimento de alternativas de produtos com a utilização de peixe livre de espinhas (BOSCOLO et al., 2009).

Produtos e subprodutos do pescado, como cortes especiais e a Carne Mecanicamente Separada (CMS) são alternativas que podem ser utilizadas, com um curto tempo de preparo, em pratos com molho, assados, grelhados, ensopados, cozidos, salsichas, empanados, eliminando as barreiras de inclusão criadas ao peixe in natura.

Essa inclusão também traz inúmeros benefícios de caráter nutricional, uma vez que, identifica-se no consumo do pescado, alto teor de gorduras poliinsaturadas, bem como a redução de níveis de colesterol e triglicerídeos, das incidências de acidente vascular cerebral, doença cardíaca, além de proteger contra o desenvolvimento de câncer, proporcionar o aumento da função cognitiva em adultos, reduz a ansiedade e a ocorrência de nascimentos prematuros e com baixo peso (BURGER, 2008; TACON; METIAN, 2013).

Isso porque o pescado é um alimento rico em proteínas de alto valor biológico, de fácil digestão, com boas concentrações de vitaminas, como $A, E$ e, principalmente, a $D$, a niacina e o ácido pantotênico. Quanto aos minerais, possui 
sódio, potássio, manganês, cálcio, ferro, fósforo, iodo, flúor, selênio, magnésio e cobalto, que regularizam as funções do corpo, melhorando a memória, a concentração e proporcionando maior desempenho escolar, melhor qualidade no sono e no metabolismo geral do organismo, trazendo benefícios à toda população (BOSCOLO et al., 2009).

Segundo Maciel et al. (2012) há evidências consistentes das propriedades benéficas de promoção da saúde em populações no qual o padrão alimentar tem o pescado como base alimentar. A melhoria da qualidade da dieta impacta diretamente na redução da ocorrência de DCNT, como diabetes, hipertensão e dislipidemia (SONATI; VILARTA, 2010).

Minozzo et al. (2008) analisaram capitais na região Sul e Sudeste do Brasil e concluíram que o pescado é um alimento que possui forte apelo de mercado gerado pela associação desta proteína com uma dieta de baixas calorias, voltada para a salubridade e longevidade. No entanto, o custo de aquisição e a falta de diversidade nas formas de acesso, ou seja, a diversificação das formas de apresentação foram citados como obstáculos ao aumento do consumo.

Neste panorama, verifica-se que o pescado é rico em proteína de alta qualidade e em muitas vitaminas e minerais, além de ter menor conteúdo de gorduras, especialmente pela alta proporção de gorduras saudáveis (insaturadas), sendo considerado excelente substitutivo para as carnes vermelhas (BRASIL, 2014).

\section{PERSPECTIVAS DE INSERÇÃO DE PRODUTOS LOCAIS E TRADICIONAIS NA GASTRONOMIA INTERNACIONAL E EM MERCADOS DE NICHO}

O estudo da alimentação vem se destacando entre os pesquisadores sociais através da ideia do sistema agroalimentar, no qual não é priorizada somente a questão da produção, mas todo o processo que articula as diversas atividades alimentares e percorre o fluxo do alimento (da produção à mesa do consumidor final) sem desprezar os atores envolvidos. Em outras palavras, os processos de plantação e colheita, produção, distribuição, preparo e consumo são percebidos de maneira interligada e sistêmica, a partir das relações existentes entre os sujeitos do processo, nos quais podemos identificar os produtores, profissionais da indústria e da pesquisa tecnológica, famílias, chefs de cozinha, além da utilização das técnicas e representações que são próprias e específicas desses atores (POULAIN, 2004; MACIEL; CASTRO, 2013).

No último elo do sistema agroalimentar, as práticas de consumo têm se voltado com mais frequência para a revalorização de produtos e processos produtivos considerados tradicionais e autênticos, numa perspectiva de relacionar a simbologia do rural a partir das transformações ocorridas no sistema urbanoindustrial, no qual o agricultor é visto, muitas vezes, como o "grande ecologista do planeta" (WILKINSON, 2006).

Para Portilho e Barbosa (2016) são diversos movimentos sociais (economia solidária, comércio justo e Slow Food) e ideologias alimentares (saudabilidade, sustentabilidde e indicação de origem) que se alinham às novas perspectivas de ressignificação do rural que atribui maior valor nos produtos com características peculiares, tais como: orgânico, agroecológico, artesanal, local, colonial e provenientes da agricultura familiar. Essa tradição ressignificada é, segundo Zaneti (2012), o elemento essencial de diferenciação na gastronomia frente à padronização cultural, onde é estabelecido numa forma de fortalecer e preservar a singularidade cultural do grupo social a que pertence esse produto ou modo de fazer.

Por outro lado, Ploeg (2010) explana que essas formas de diferenciação do alimento consumido estão sendo demandadas pelas classes de renda mais elevada 
que privilegiam a proximidade da produção, assim como ocorre em circuitos curtos de comercialização como as feiras. O autor sinaliza que apesar do crescimento dessas formas de encadeamento da produção possa ser considerado como uma contra tendência à globalização, essas relações tem sido predominadas em mercados de nichos que se apropriam dessas qualidades.

A partir dessas tendências é considerado que a construção social de mercado para os produtos agroalimentares tradicionais baseia-se frente às movimentações entre dois mundos de mercado que se entrelaçam. Um com foco na cultura, na tradição e no simbólico e o outro com ênfase na eficiência, na utilidade e na relação entre preço e quantidade (ZANETI, 2012), ou seja, lógicas do mercado alternativo e do mercado convencional, respectivamente.

A efervescência de movimentos sociais e políticos, como os supracitados, estão focados em mobilizar os diferentes atores na esfera do consumo, numa tentativa de construir um tipo de "agenda da mesa da cozinha", nos quais questões globais são trazidas para a esfera das práticas tradicionais e cotidianas (PORTILHO; BARBOSA, 2016).

No caso da gastronomia, essa perspectiva se materializa ao ser exemplificado dois processos antagônicos e concomitantes que vem ocorrendo em dois setores da sociedade, conforme relatou Zaneti (2012). De um lado, as empresas multinacionais de fast food se multiplicam por toda a parte, nas quais os pratos estão cada vez mais padronizados, podendo-se encontrar ingredientes de várias localidades em uma mesma refeição. Por outro lado, encontra-se um maior número de chefs aderindo a fusion cuisine (cozinha de fusão) e a cuisine du terroir (cozinha da terra) que utilizam elementos regionais e tradicionais com técnicas da gastronomia clássica ou contemporânea, além de aderir aos princípios do Slow Food $^{3}$. Neste contexto,

o valor dos bens singulares coaduna-se com as novas tendências da gastronomia que buscam trazer para a cozinha alimentos frescos, regionais e tradicionais, que respeitem tanto a sustentabilidade ambiental quanto a sociocultural promovendo sabores diferenciados nos preparos e comércio justo ao longo de sua cadeia. A gastronomia encontra-se em uma tendência que baseia seu consumo - as escolhas dos chefs para os preparos - nas premissas do comércio justo e verde, que, atualmente mostra-se como uma tendência global tanto de consumo, quanto de produção, contextualizando, portanto, a gastronomia interligada com os processos globais (ZANETI, 2012, p. 3).

Assim, a gastronomia moderna se rendeu aos alimentos tradicionais e à combinação de novas técnicas e métodos tradicionais (savoir faire - saber fazer) para extrair os sabores dos ingredientes. A gastronomia, como parte importante da cultura intangível de um povo, promove o contato do comensal com a realidade visitada, proporcionando, no sentido figurado e literal, uma degustação dos ritos, valores e tradições locais trazendo benefícios para o consumidor e comunidade local (OLIVEIRA; KATO, 2015).

\footnotetext{
${ }^{3}$ Os princípios do Slow food estão conectados no direito ao prazer da alimentação, utilizando produtos artesanais de qualidade especial, produzidos de forma que respeite tanto o meio ambiente quanto as pessoas responsáveis pela produção, numa perspectiva que prega o que é bom, limpo e justo (ZANETI, 2012).
} 
Botelho (2008) explica que a gastronomia tem caráter identitário e que, muita das vezes se interliga à história local de um povo. A culinária se expressa não somente por fatores físicos de sua geografia, mas também nos aspectos humanos, econômicos, sociais e culturais. A autora destaca que

podemos, por meio de um processo de engenharia reversa, desconstruir uma receita para encontrarmos os produtos agrícolas e as técnicas de cultivo, os temperos utilizados e o tipo de pecuária dominantes em uma região. Mas o prato não se resume a seus aspectos materiais. É necessário, também, que façamos uma arqueologia dos sabores, ou seja, uma dedução do tipo de clima e solo principais, dos grupos étnicos presentes, das migrações existentes, das influências exteriores, bem como das características culturais (BOTELHO 2008, p. 62).

Menasche e Maciel (2003) sinalizam que a identidade da cozinha regional brasileira é diversa tão quanto são as especificidades das regiões do país. Essa significativa diversidade regional não deve relacionar apenas aos aspectos físicos, mas as condições históricas e de apropriação e colonização do território nacional. Assim, cada região tem seus próprios hábitos alimentares e seus pratos simbólicos, que servem como marcadores identitários regionais. Por isso, alguns pratos são associados à região de origem e de sua população, como é o arroz com pequi de Goiás e o acarajé e o vatapá da Bahia.

Neste contexto, a gastronomia brasileira é entendida como

\begin{abstract}
um prato cheio de histórias, regado à cultura de diferentes povos, fatos econômicos e políticos e ingredientes que romperam as barreiras geográficas tanto nacionais, quanto internacionais. Temperada pela biodiversidade única presente nos seis diferentes biomas que acalcam o solo brasileiro, a culinária do Brasil é recheada de um dinamismo intercultural singular, proveniente dos diversos fluxos migratórios externos e internos, que veicularam valores, hábitos culturais $e$ alimentares, moldando a cultura e a identidade gastronômica do país, proporcionando a ela o título de uma das cozinhas mais miscigenadas do mundo (ZANETI, 2012, p. 52).
\end{abstract}

Considera-se, portanto, que a gastronomia brasileira dispõe de um rico potencial de biodiversidade que reúne na fauna e na flora, além dos agricultores e povos tradicionais possuidores de saberes e modo de fazer particulares, um patrimônio e identidade cultural de características únicas que viabilizam a produção de alimentos saudáveis e funcionais, com o uso de variados ingredientes locais e tradicionais aliados à valorização dos ingredientes nativos no preparo das refeições.

\title{
4 ESTRATÉGIAS DE INSERÇÃo DE PEIXES NATIVOS NA GASTRONOMIA: A EXPERIÊNCIA DA EMBRAPA
}

Tendo em vista que no Brasil a espécie de peixe mais produzida e uma das mais consumidas é a tilápia (espécie exótica), reconhece a importância das pesquisas, conhecimentos e tecnologias geradas pela Embrapa que estão sendo direcionadas em prol das espécies nativas sem apelo comercial e com pouco desenvolvimento tecnológico. Na perspectiva de estruturar essa cadeia produtiva, a Embrapa selecionou algumas espécies nativas brasileiras como a matrinxã (Brycon 
sp), o pintado (Pseudoplatystoma), o tambaqui (Colossoma macropomum) e o pirarucu (Arapaima gigas), a fim de desenvolver tecnologias de produção para aumentar a oferta e criar nichos de mercado.

Carvalho, Oliveira e Fonseca (2017) reforçam que o pescado no contexto nacional, carrega em si não apenas o caráter de atividade que promove a geração de renda das famílias que dela dependem, mas também carrega inúmeras questões do tecido social identificável com esta ocupação, estando o peixe, portanto ligado fortemente à questão cultural e aos hábitos alimentares de determinada região.

Ainda que a Embrapa tenha maior foco na pesquisa e inovação agropecuária, a empresa está se sensibilizando com todos os elos do sistema agroalimentar, incluindo os desafios para o consumo de uma alimentação adequada, saudável e sustentável. Indo ao encontro desse desafio, o estudo de Reed et al. (2013) relata que há uma necessidade do mercado organizar uma gastronomia que utilize de espécies de peixes da localidade e os direcionem como produto diferenciado, o que necessitaria de pesquisas.

É fundamental também que a extensão rural esteja atenta à emergência dessas tendências ligadas às novas "ruralidades", ou seja, dinâmicas culturais e socioambientais que devem ser melhor exploradas no intuito de agregar valor às práticas e produtos principalmente oriundas das pequenas propriedades (CERETTA; SANTOS, 2013).

Neste intento, esta seção irá descrever experiências da Embrapa que articulam ações de inserção de peixes nativos na gastronomia em três eixos: na alimentação escolar, no enlatamento para a indústria de conservas e para a culinária japonesa.

\subsection{PEIXES NATIVOS COMO ALTERNATIVA PARA A ALIMENTAÇÃO ESCOLAR}

A Embrapa Pesca e Aquicultura, localizada em Palmas/TO, e parceiros reuniram-se em torno da constatação das dificuldades enfrentadas pelos agricultores familiares (Inclui-se os pescadores artesanais e os aquicultores familiares conforme a Lei $\mathrm{n}^{0} 11.326 / 2006$ ) na comercialização do pescado no mercado formal e na baixa participação no mercado institucional, bem como a falta de inspeção sanitária nos municípios menores do Estado (SOUSA et al., 2016).

Num estudo sobre o mapeamento da inclusão do pescado na alimentação escolar elaborado pelo Ministério da Pesca e Aquicultura (MPA, 2012), evidenciouse que em apenas $34 \%$ das escolas pesquisadas houve inclusão do pescado neste tipo de refeição, seja no fornecimento semanal ou até na periodicidade eventual/esporádica. Analisando os resultados dos principais fornecedores, verificou-se que a maioria foram as grandes indústrias/frigoríficos/atacados com $56 \%$ e o varejo com $24 \%$. Já os pescadores artesanais e aquicultores familiares (entrega individual) e suas colônias/associações/cooperativas (entrega coletiva) foram responsáveis por $15 \%$ e $13 \%$, respectivamente.

Para os que responderam pela não inclusão do pescado na alimentação escolar, observou-se que os principais motivos alegados foram: $54 \%$ apontaram a dificuldade de acesso aos fornecedores, $47 \%$ pela falta de fornecedores/ausência de produtos no mercado e a mesma porcentagem para o risco de espinhas, $42 \%$ custo elevado do pescado e $35 \%$ alegaram a questão da inadequada infraestrutura para armazenamento/conservação (MPA, 2012).

No Tocantins, há o apoio por meio de ações governamentais voltadas à alimentação escolar com a criação da Instrução Normativa no 06/2013 referente à inserção do pescado no cardápio do Programa de Alimentação da Rede Estadual de Ensino do Tocantins, o qual tem o objetivo de atender a periodicidade de duas vezes 
na semana e utilizar-se da tecnologia de CMS ou o filé de peixe sem espinha que deve atender ao disposto na legislação sanitária. Entretanto, a principal barreira é a falta de fornecedores de pescado, provenientes da agricultura familiar, aptos para o acesso à inspeção sanitária a fim de atender as demandas das escolas da rede pública de ensino. Até o ano de 2015 não havia nenhuma unidade processadora da agricultura familiar que atendia a estas exigências no Estado (SOUSA et al., 2016; SOUSA; CHARÃO-MARQUES; KATO, 2017).

Devido a esses problemas diagnosticados e por falta de um entreposto coletivo no Tocantins, foram mobilizadas diversas colônias de pescadores a fim de buscar soluções para os problemas específicos de cada realidade.

A principal estratégia de comercialização envolveu um frigorífico privado, localizado em Aliança/TO, que visou em um primeiro momento a realização de testes para o cálculo de rendimento da produção de CMS para algumas espécies nativas do Rio Araguaia. Num segundo momento, foram estabelecidos parâmetros para o cálculo do custo do serviço de abate e do processamento da CMS de pescado a ser repassado para as colônias e cooperativas de pescadores que iriam remunerar por este tipo de serviço feito pelo frigorífico a fim de acessar as compras institucionais. Dito de outra forma, por não terem entreposto com o selo de inspeção sanitária, utilizaram de uma estrutura privada para obtê-lo e, assim, ter o direito as políticas públicas do mercado institucional. Após essa negociação entre a organização associativa dos pescadores e o frigorífico, a logística para pegar os peixes na colônia ficou a cargo do frigorífico, enquanto a entrega da CMS para as instituições sem fins lucrativos ficou sob a responsabilidade do Programa Mesa Brasil do Serviço Social do Comércio (SESC). Outras estratégias específicas foram adotadas como relatado no estudo de Sousa et al. (2016).

Além das estratégias de comercialização estabelecidas, o projeto focou em trabalhar o público realcionado à alimentação escolar (merendeiras, nutricionistas, corpo técnico de escolas) acerca da importância da inserção do pescado enquanto fonte protéica de alto valor biológico e de fácil preparo nas cozinhas escolares, já que a dificuldade no preparo e presença de espinhas foram apresentados como entrave à inserção.

Foram então desenvolvidas oito preparações e testadas em escolas públicas de Palmas (KATO et al., 2017), as quais originarão um livro de receitas voltados ao uso do pescado na alimentação escolar, bem como publicações direcionadas ao público infantil sobre a importância deste consumo. Os resultados dos testes de aceitação sugerem a importância do estímulo à ingestão de pescado ainda durante as fases iniciais da vida escolar, já que a aceitação tende a ser maior em alunos das séries iniciais. Tais políticas de inserção seriam então de fundamental importância para a ampliação do mercado consumidor de pescado no futuro.

\subsection{PEIXES NATIVOS COMO ALTERNATIVA DE ENLATAMENTO PARA A INDÚSTRIA DE CONSERVAS}

A sardinha (Sardinella brasiliensis) é a espécie de pescado mais popular entre os brasileiros, consumida sob a forma de conserva ou enlatada, principalmente nas regiões norte e nordeste do país, por ser uma fonte de proteína acessível às populações de baixa renda, o que contribui consideravelmente para a segurança alimentar e nutricional deste público. Nos últimos 40 anos, tem-se registrado um declínio em torno de $30 \%$ dos estoques naturais de sardinha. Para assegurar a proteção da sua reprodução foi instituído o período de defeso, uma vez que não há 
estabilidade dos estoques, devido à grave situação da pesca excessiva dos cardumes em determinados períodos (SOUSA et al., 2014).

A indústria de enlatamento de pescado no Brasil se desenvolveu através do processamento de conservas da sardinha verdadeira em óleo vegetal. Este produto representou 95\% da produção total de enlatados na década de 1970, declinando nos anos posteriores. O esforço da pesca e concentração do processamento sobre uma única espécie vem acarretando uma série de problemas do ponto de vista da disponibilidade de pescado e da relação com o consumo (ANTUNES, 1984). Cergola e Dias Neto (2011) ressaltam que houveram grandes variações intra-anuais da captura de sardinha verdadeira, com queda de $30 \%$ no período compreendido de 2009 a 2010. Isto se reflete na busca pela matéria-prima cada vez mais distante do local do processamento ou no aumento da importação, o que onera mais o custo da produção.

A proibição da pesca com o período do defeso gera alta dependência dessa matéria-prima que se torna importada, sendo um importante gargalo ao setor da indústria nacional de conserva de pescado. Por outro lado, espécies nativas ainda não exploradas comercialmente, como a sardinha de água doce e espécies já cultivadas no mercado, como a matrinxã têm grande potencial para serem utilizadas pela indústria enlatadora, por ambas apresentarem características como sabor bem apreciado pelos consumidores, rápido crescimento, boa conversão alimentar e formato adequado ao enlatamento (SOUSA et al., 2014).

Neste contexto, a Embrapa realizou a prospecção de espécies nativas, como as supracitadas, como alternativa para o processo de enlatamento para a indústria de conservas de pescado. Entre os resultados, observou-se uma boa aceitação de mercado e intenção de compras das espécies de peixe prospectadas (matrinxã e sardinha de água doce), dinamizando o setor das indústrias de conservas a partir da introdução de novas espécies e criação de novos nichos de mercado, uma vez que a indústria demanda por um peixe nativo que seja proveniente de cultivo e com produção em escala (SOUSA et al., 2014).

A sardinha de água doce, por apresentar características favoráveis à indústria de conservas, tais como rápido crescimento, relativo custo baixo de produção, boa conversão alimentar e formato adequado ao enlatamento, apresentou potencial para nichos de mercado associados aos produtos de preços baixos, direcionados à população menos favorecida. Porém, mais estudos são necessários para avaliar a viabilidade econômica dessa matéria-prima considerando custos fixos e variáveis, bem como desenvolvimento de tecnologias de produção, uma vez que ainda não é produzida em escala comercial (SILVA et al., 2016; SOUSA et al., 2014).

No caso da matrinxã, novos estudos seriam necessários para avaliar a viabilidade do posicionamento desta espécie como produto alternativo em um nicho de mercado gourmet, com preço diferenciado, a exemplo do que se observa em algumas indústrias que operam com pescados nobres enlatados. Justifica-se esta opção, dado o custo elevado do alevino de matrinxã, uma vez que as fases de reprodução e larvicultura apresentam limitações, tais como o canibalismo frequente nestas fases, o que leva a uma redução na taxa de sobrevivência e menor disponibilidade de alevinos no mercado, elevando os custos da produção. Sendo assim, a matrinxã apresentou potencial de comercialização em nichos de mercado gourmet, devido ao custo mais elevado para a sua venda (CHICRALA et al., 2015; SANTOS et al., 2015).

Portanto, verificou-se que a utilização de matéria-prima, como os peixes nativos provenientes da aquicultura, para a indústria de conservas permite maior constância no fornecimento devido à possibilidade de planejamento da despesca, 
para o atendimento da demanda da indústria, além de contribuir para a redução dos problemas relacionados à pesca extrativista.

\subsection{PEIXES NATIVOS COMO ALTERNATIVA PARA A CULINÁRIA JAPONESA}

A culinária japonesa é diferenciada em seu modo de preparo, seus sabores e sua apresentação, devido a vários fatores, do histórico aos culturais, constituindose numa cozinha recheada de ritos e tradições, marcada pela característica da saudabilidade e composta pela tríade: arroz, verduras e proteína animal (fundamentalmente peixes) (KATO et al., 2016).

Segundo Figueiredo (2009), assim como resultado das migrações entre os povos, a gastronomia também é influenciada por diferentes culturas que se fundem, o que chamamos de hibridismo e verificamos na cozinha de fusão que articula novas técnicas com ingredientes tradicionais de uma população. Dessa forma, "a integração de peixes nativos amazônicos a esta culinária, não apenas favoreceria a valorização do ingrediente, preservando suas características de fresco, tão valorizada nesta cozinha, além da promoção do ingrediente local" (KATO et al., 2016, p. 107).

Assim, como forma de substituir ou ter alternativas aos peixes já utilizados na culinária japonesa, como o salmão, que tem elevado custo, foi proposto o desenvolvimento de um cardápio de pratos frios e quentes utilizando peixes cultivados nativos da região amazônica que foram preparados com técnicas da culinária japonesa. Para isso, foi utilizado a manta e o lombo do pirarucu e a costela de tambaqui, a partir de novos cortes, na preparação de quatro preparações que foram usadas para o teste da análise sensorial e da intenção de compras dos consumidores (KATO et al., 2016).

Portanto, verificou-se que com esses testes boa aceitação e intenção de compra por parte dos consumidores. O preparo de peixes nativos, principalmente da Amazônia, utilizando técnicas da culinária japonesa reforça a conhecida versatilidade dos ingredientes do bioma amazônico e da localidade, como alternativa aos restaurantes japoneses que poderão ter neste emergente ingrediente mais outra fonte de inspiração, sabores e inovação para seus cardápios. Essa interface ou cozinha de fusão não apenas cria novas oportunidades de mercado para o peixe nativo como também fornece mais uma alternativa aos empreendimentos do ramo que atualmente são altamente dependentes da flutuação de preços de peixes importados fazendo com que o ticket médio desses estabelecimentos seja sempre classificado como elevado (KATO et al., 2016).

\section{CONSIDERAÇÕES FINAIS}

Conclui-se que nessas estratégias de substituição de produtos globais por locais, como ocorre com os peixes nativos, novas hibridizações na gastronomia vêm sendo criadas, a partir de novos produtos (CMS na alimentação escolar e nova matéria-prima para enlatamentos para a indústria de conservas) e novos cortes (culinária japonesa e outras internacionais), acarretando em novas identidades culturais e formas de consumo.

Por isso, a importância de iniciativas como da Embrapa e demais órgãos de inovação em continuar pesquisando e desenvolvendo tecnologias para os peixes nativos, a fim de oferecer alternativas a diversos setores de alimentos e bebidas do Brasil, dos mercados institucionais à alta gastronomia, que ofereçam qualidade a um preço bem mais competitivo. 
É necessário também que esta inovação englobe os técnicos da extensão rural que necessitam estar capacitados, a fim de garantir aos produtores o acesso a informações de potenciais mercados para a sua devida inserção, garantindo a exploração de recursos ambientalmente sustentável, economicamente viável e socialmente justo, buscando em novas intervenções formas de proporcionar ao produtor (principalmente os pequenos) abordagens cada vez mais vantajosas de agregação de valor na cadeia produtiva da piscicultura.

\section{REFERÊNCIAS}

ABRANDH - Ação Brasileira pela Nutrição e Direitos Humanos. Relatório de pesquisa: Agricultura familiar, alimentação escolar e a realização do direito humano à alimentação adequada. Brasília, 2012.

ANTUNES, S. A. Processamento, parâmetros de qualidade e espécies de atuns e bonitos no desenvolvimento da indústria de enlatamento de pescado no Brasil. Brasília, DF: SUDEPE, 1984.

BOSCOLO, W. R.; FEIDEN, A.; MALUF, M. L. F.; VEIT, J. C. Peixe na merenda escolar: educar e formar novos consumidores. Toledo: GFM, Gráfica \& Editora, 2009.

BOTELHO, A. Geografia dos sabores: ensaio sobre a dinâmica da cozinha brasileira. Revista Textos do Brasil. ed. n. 13 - Sabores do Brasil, p. 61-69, 2008.

BURGER, J. Fishing, fish consumption, and awareness about warnings in a university community in central New Jersey in 2007, and comparisons with 2004. Environmental Research, New York, v. 108, p. 107-116, 2008.

BRASIL. Resolução FNDE/CD/№ 32/2006. Estabelecer normas para execução do PNAE, 2006.

BRASIL. Resolução FNDE №38/2009. Dispõe sobre o atendimento da alimentação escolar aos alunos da educação básica no Programa Nacional de Alimentação Escolar - PNAE, 2009.

BRASIL. Guia alimentar para a população brasileira. Ministério da Saúde, Secretaria de Atenção à Saúde, Departamento de Atenção Básica. 2ª . ed. Brasília: Ministério da Saúde, 2014. Disponível em: <http://portalarquivos.saude.gov.br/images/pdf/2014/novembro/05/Guia-Alimentarpara-a-pop-brasiliera-Miolo-PDF-Internet.pdf>. Acesso em: 20 abr. 2017.

CARVALHO, N. F.; OLIVEIRA, M. L. R.; FONSECA, B. C. De pescadores artesanais a piscicultores: a mudança nos meios de vida entre os pescadores atingidos pela construção da Usina Hidrelétrica do Funil. Revista Extensão Rural, Santa Maria, v. 24, n. 1, p. 79-99, 2017. Disponível em: https://periodicos.ufsm.br/extensaorural/article/view/12411.

CERETTA, C. C.; SANTOS, N. R. Z. O papel da extensão rural e a abordagem do turismo junto as pequenas propriedades rurais. Extensão Rural, Santa Maria, v. 20, n. $2, \quad$ p. 7-29, 2013. Disponível em: https://periodicos.ufsm.br/extensaorural/article/view/6678. 
CERGOLA, M. C.; DIAS NETO, J. Plano de Gestão para o Uso Sustentável da Sardinha-verdadeira do Brasil. In: CERGOLA, M. C.; DIAS NETO, J. (Orgs). Série Plano de Gestão dos Recursos Pesqueiros. Brasília-DF: Ibama, 2011.

CHICRALA, P. C. M. S.; SANTOS, V. R. V.; SOUSA, D. N.; LUIZ, D. B.; FREITAS, D. G. C.; PARANHOS, A. B. Enlatamento de matrinxã (Brycon Amazonicus): descrição do processo na indústria. Série Embrapa, v. 1, p. 1-24, 2015.

FAOSTAT. Evolução do consumo de pescado per capita no Brasil. 2016. Disponível em <http://faostat.fao.org/beta/en/\#data/CL/visualize>. Acesso em: 8 nov. 2016.

FIGUEIREDO, F. B. Patrimônio imaterial e turismo: a cultura gastronômica do agnolini. $141 \mathrm{f}$. Dissertação (Mestrado em Turismo). Universidade de Caxias do Sul, Rio Grande do Sul, 2009.

IBGE - INSTITUTO BRASILEIRO DE GEOGRAFIA E ESTAtísticA. Pesquisa Nacional de Amostra de Domicílios 2008: síntese dos indicadores. Rio de Janeiro: Instituto Brasileiro de Geografia e Estatística, 2009. Disponível em: <http://www.ibge.gov.br/home/estatistica/populacao/trabalhoerendimento/pnad2008/ >.Acesso em: 10 jan. 2017.

IOM - INSTITUTE OF MEDICINE. Dietary reference intakes: applications in dietary planning. Washington, DC: National Academies Press, 2002.

KATO, H. C. A.; DA SILVA MACIEL, E.; QUARESMA F. R. P.; FREITAS, A. A Acceptance of Dishes based on Mechanically Separated Meat of Tambaqui (Colossoma macropomum) in a Public School, Brazil. Food Science and Nutrition Technology, v. 2, n. 1, 2017.

KATO, H. C. A.; FREITAS, A. A. Panorama of the aquaculture expansion and the fish consumption in Brazil. Journal of FisheriesSciences.com, v. 9, n. 3, p. 80-83, 2015.

KATO, H. C. A.; OLIVEIRA, L. S.; MACIEL, E. S.; FREITAS, A. A. A cozinha de fusão encontra o rio: peixes nativos amazônicos como alternativa para a culinária japonesa. Applied Tourism, v. 1, n. 2, p. 97-114, 2016.

MACIEL, M. E.; CASTRO, H. C. A comida boa para pensar: sobre práticas, gostos e sistemas alimentares a partir de um olhar socioantropológico. Demetra, v. 8, p. 321328, 2013.

MACIEL, E. S.; VASCONCELOS, J. S.; SONATI, J. G.; SVAAY-DA-SILVA, L. K.; GALVÃO, J. A.; OETTERER, M. Perfil dos voluntários de universidade brasileira a respeito do consumo de pescado. Segurança Alimentar e Nutricional, Campinas, v. 19, n. 1, p. 60-70, 2012.

MENASCHE, R.; MACIEL, M. Alimentação e cultura, identidade e cidadania. Revista Democracia Viva. Especial Segurança Alimentar no 16. Rio de Janeiro: Ibase; mai./jun., v. 3, n. 7, 2003. 
MINOZZO, M. G.; HARACEMIV, S. M. C.; WASZCZYNSKYI, N. Perfil dos consumidores de pescado de São Paulo (SP), Toledo (PR) e Curitiba (PR) no Brasil. Revista Alimentação Humana, v. 14, n. 3, p. 133-14, 2008.

MPA - Ministério da Pesca e Aquicultura. Mapeamento da inclusão do pescado na alimentação escolar. Brasília: MPA, 2012. Disponível em: <http://webcache.googleusercontent.com/search?q=cache:xAckzGOuXxQJ:www.fnd e.gov.br/arquivos/category/116-alimentacao-escolar\%3Fdownload\%3D8692:notatecnica-n-04-2013-inclusao-de-pescado-na-alimentacao-escolar+\&cd=2\&hl=pt$\mathrm{BR} \& \mathrm{ct}=\mathrm{clnk} \& \mathrm{gl}=\mathrm{br}>$. Acesso em: 10 jan. 2017.

OLIVEIRA, L. S.; KATO, H. C. A. Considerações sobre o Turismo Gastronômico na Amazônia: o caso do roteiro gastronômico Expedição Amazônia no estado do Pará. Caderno de Estudos e Pesquisa em Turismo, v. 4, n .4, p. 121-138, 2015.

PLOEG, J. D. The Food Crisis, Industrialized Farming and the Imperial Regime. Journal of Agrarian Change, v. 10, n. 1, p. 98-106, 2010.

PORTILHO, F.; BARBOSA, L. A adesão à causa rural e da agricultura familiar por consumidores e seus movimentos organizados. In: MARQUES, F.C.; CONTERATO, M.; SCHNEIDER, S. (Orgs.). Construção de mercados para a agricultura familiar: desafios para o desenvolvimento rural. Porto Alegre: Editora da UFRGS, 2016 , v. 1, p. 251-273.

POULAIN, JP. Sociologias da alimentação: os comedores e o espaço social alimentar. Florianópolis: UFSC, 2004.

REED, M.; COURTNEY, P.; URQUHART, J.; ROSS, N. Beyond fish as commodities: Understanding the socio-cultural role of in shore fisheries in England. Marine Policy, v. 37, p. 62-68, 2013.

SA, N. N. B.; MOURA, E. C. Fatores associados à carga de doenças da síndrome metabólica entre adultos brasileiros. Cad. Saúde Pública, Rio de Janeiro, v. 26, n. 9, p. 1853-1862, set. 2010.

SANTOS, V. R. V.; FREITAS, D. G. C.; CHICRALA, P. C. M. S.; SOUSA, D. N.; LUIZ, D. B. A matrinxã como alternativa para enlatamento: avaliação da aceitação e da intenção de compra. Série Embrapa, v. 1, p. 1-24, 2015.

SILVA, C. D. M.; PIRES, C. R. F.; SOUSA, D. N.; CHICRALA, P. C. M. S.; SANTOS, V. R. V. Avaliação sensorial de matrinxã (brycon amazonicus) enlatada com cobertura de óleo vegetal. Journal of bioenergy and food Science (JBFS), v. 3, n. 3, p.149-160, 2016.

SOFIA. The state of world fisheries and aquaculture. FAO: Roma, 2016. Disponível em: <http://www.fao.org/fishery/sofia/en>. Acesso em: 10 jan. 2017.

SONATI, J.; VILARTA, R. Novos padrões alimentares e as relações com os domínios da qualidade de vida e saúde. In: VILARTA, R. (Org.). Novos padrões alimentares e as relações com os domínios da qualidade de vida e saúde. Campinas: IPES, 2010. p. 85-91. 
SOUSA, D. N. Os estudos de extensão pesqueira nos Programas de PósGraduação em Extensão Rural. Extensão Rural, Santa Maria, v. 21, p. 32-51, 2014. Disponível em: https://periodicos.ufsm.br/extensaorural/article/view/9092.

SOUSA, D. N.; CHICRALA, P. C. M. S.; SANTOS, V. R. V. Prospecção de espécies de peixes nativos como alternativas ao uso da sardinha-verdadeira. In: IX Congresso Latino Americano de Sociologia Rural - ALASRU, 2014, Cidade do México. Anais..., 2014.

SOUSA, D. N.; ALMEIDA, H. C. G.; MILAGRES, C. S. F.; NIEDERLE, P. A. Transferência de tecnologia e estratégias de comercialização do pescado da agricultura familiar para a alimentação escolar: a experiência da Embrapa no estado do Tocantins. In: Congresso da Sociedade Brasileira de Economia, Administração e Sociologia Rural - SOBER, 2016, Maceió. Anais ..., 2016.

SOUSA, D. N.; CHARAO-MARQUES, F.; KATO, H. C. A. Novo programa, novos atores: inovação e agroecologia na agricultura familiar do Tocantins. Extensão Rural, Santa Maria, v. 24, p. 44-62, 2017. Disponível em: https://periodicos.ufsm.br/extensaorural/article/view/27765.

TACON, A. G. J.; METIAN, M. Fish matters: importance of aquatic foods in human nutrition and global food supply. Reviews in Fisheries Science, v. 21, n. 1, p. 22-38, 2013.

ZANETI, T. B. Das panelas das nossas avós aos restaurantes de Alta Gastronomia: os processos sociais de valorização de produtos agroalimentares tradicionais. 182 f. Mestrado em Agronegócios. Universidade de Brasília. Brasília/DF, 2012.

ZUIN, L. F. S.; ZUIN, P. B. Produção de alimentos tradicionais contribuindo para o desenvolvimento local/regional e dos pequenos produtores rurais. Revista Brasileira de Gestão e Desenvolvimento Regional, v. 4, n. 1, 2008.

WILKINSON, J. Fish: A Global Value Chain Driven on the Rocks. Sociologia Ruralis, v. 46, p. 139-154, 2006. 